\title{
Feed-based vaccination regime against streptococcosis in red tilapia, Oreochromis niloticus x Oreochromis mossambicus
}

\author{
M. S. Ismail ${ }^{1}$, A. Siti-Zahrah ${ }^{2}$, M. R. M. Syafiq ${ }^{2}$, M. N. A. Amal ${ }^{3}$, M. Firdaus-Nawi ${ }^{1}$ and M. Zamri-Saad ${ }^{1,4^{*}}$
}

\begin{abstract}
Background: Streptococcosis is an important disease of tilapia throughout the world. In Malaysia, streptococcosis outbreak was commonly reported during the 3-month period of high water temperature between April and July. This study describes the duration of protection following single and double booster dose regimes against streptococcosis in tilapia using a feed-based vaccine containing formalin-killed Streptococcus agalactiae. A total of 510 tilapias of $120 \pm 10 \mathrm{~g}$ were selected and divided into 3 groups. Fish of Group 1 were vaccinated at weeks 0 and 2 (single booster group) while fish of Group 2 were vaccinated at weeks 0, 2 and 6 (double booster group) with a feed-based vaccine against streptococcosis. Fish of Group 3 was not vaccinated. Serum samples were collected weekly to determine the antibody level while samples of eye, brain and kidney were collected for bacterial isolation. At week 10, all fish were challenged with live S. agalactiae and the survival rate was determined.

Results: Both vaccinated groups showed significant $(p<0.05)$ increase in the antibody levels following the first booster dose, which lasted until week 6. Group 2 showed consistent high level of antibody following the second booster dose at week 6 and remained high until week 12. Challenge trial at week 10 resulted in $45 \%, 70 \%$ and $0 \%$ rate of survival for Groups 1, 2 and 3, respectively.
\end{abstract}

Conclusion: Double booster regime is most suitable to be applied for feed-based vaccination against streptococcosis prior to the start of the hot season.

Keywords: Vaccination regime, Streptococcosis, Red tilapia, Feed-based vaccine

\section{Background}

Tilapia is one of the most cultured fish species in the world with China, Egypt and Philippines as major producers [1]. However, with extensive aquaculture activity, farmed fish are affected by environmental fluctuations and husbandry management, which cause stress to the fish and contribute to infections by a wide variety of pathogens [2].

Streptococcosis is one of the major diseases of fish that leads to staggering losses. It is caused by two main species; Streptococcus agalactiae and S. iniae, affecting a wide range of both freshwater and marine fish species. In

\footnotetext{
* Correspondence: mzamri@upm.edu.my

'Department of Veterinary Laboratory Diagnosis, Faculty of Veterinary

Medicine, Universiti Putra Malaysia, 43400 Serdang, Malaysia

${ }^{4}$ Present address: Institute of Bioscience, Universiti Putra Malaysia, 43400

Serdang, Malaysia

Full list of author information is available at the end of the article
}

Malaysia, most outbreaks of streptococcosis in tilapia are caused by $S$. agalactiae that are influenced by the high water temperature above $31{ }^{\circ} \mathrm{C}$ during the hot months of April to July [3].

Vaccination is the most viable option to control streptococcosis in fish [2]. Injection is the most potent route of vaccination as it produces a stronger immune response compared to other routes of vaccination such as spray and immersion $[4,5]$. However, the injection method requires a certain level of manpower, technical prowess and proper equipment. Therefore, a more practical route of vaccination is the oral route as there is no direct contact between handler and fish [6]. Furthermore, no specific technical skill is needed to apply the vaccine to the fish. However, oral vaccination results in lower efficacy and shorter period of protection [2]. This paper determines the duration of systemic IgM response and efficacy of the newly developed 
feed-based vaccine against challenge by field strain of S. agalactiae.

\section{Methods \\ The fish}

Red tilapia (Oreochromis mossambicus x O. niloticus) fingerlings of approximately $2 \mathrm{in}$. in length were acquired from a hatchery in Tapah, Perak. Upon arrival at the experimental station, the fish were kept in 2 thousand litres capacity fibreglass tanks at $27{ }^{\circ} \mathrm{C}$ with running water and aerators. The fish were fed ad-libitum twice daily until they reached approximately $100 \mathrm{~g}$ bodyweight. Prior to the start of the experiment, the fish were screened for bacterial colonization and antibody level to ensure that they were free from infection by $S$. agalactiae [7].

\section{Bacterial culture}

Streptococcus agalactiae strain TP 749B was used in this study. The strain was isolated from an outbreak of streptococcosis in cage-cultured red tilapia in 2007 at Sungai Pahang, Malaysia [8]. The stock that was kept in glycerol at $-20{ }^{\circ} \mathrm{C}$ was thawed to room temperature overnight prior to use.

\section{Formalin-killed bacteria}

The formalin-killed bacteria for vaccine preparation were prepared according to the method of Firdaus-Nawi et al. [6]. Briefly, stock culture of S. agalactiae (TP 749B) was streaked onto $5 \%$ blood agar and incubated at $30{ }^{\circ} \mathrm{C}$ for $24 \mathrm{~h}$. Propagation of S. agalactiae was done by inoculating 10 colonies from the blood agar into Brain Heart Infusion Broth (BHIB) and incubated in a shaker incubator at $150 \mathrm{RPM}, 30{ }^{\circ} \mathrm{C}$ for $24 \mathrm{~h}$. Following incubation, the bacterial concentration was determined using the standard plate count technique [9]. The $S$. agalactiae cells were then harvested by centrifugation $(6000 \times \mathrm{g}, 10 \mathrm{~min})$ and washed with phosphate-buffered saline (PBS) followed by centrifugation $(6000 \times \mathrm{g}, 10 \mathrm{~min})$ for 3 times to remove the medium residue. Afterwards, $10 \%$ buffered formalin was added into the washed pellet to reach a final concentration of $0.5 \%$ formalin before the mixture was kept overnight at $4{ }^{\circ} \mathrm{C}$ to kill the bacteria. Then, the bacteria cells were washed again with PBS with centrifugation $(6000 \times \mathrm{g}, 10 \mathrm{~min})$ for 3 times to remove the formalin residue from the culture. The formalin-killed bacteria were re-suspended in sterile PBS solution to obtain the final bacteria concentration of $6.7 \times 10^{7} \mathrm{CFU} / \mathrm{mL}$. The suspension was streaked onto blood agar and incubated for $24 \mathrm{~h}$ at $37{ }^{\circ} \mathrm{C}$ to ensure that all S. agalactiae were killed. To improve the vaccine antigenicity, Freund's incomplete adjuvant (FIA) was added to a final concentration of
$10 \%$ before it was thoroughly mixed with pelletted feed to give a final concentration of $10^{6}$ cells $/ \mathrm{kg}$ of feed [6].

\section{Experimental design}

A total of 510 red tilapia hybrid (Oreochromis mossambicus $\mathrm{x}$ O. niloticus) fish with an average weight of $120 \pm$ $10 \mathrm{~g}$ were selected and equally divided into 3 groups; the single booster, double booster and control groups. Ten fish were placed into each of the 51 glass aquaria containing $100 \mathrm{~L}$ water at an average water temperature of $29{ }^{\circ} \mathrm{C}$, provided with aeration and running water with 12-h light and dark periods. The fish were fed with commercial feed (Cargill, Malaysia).

At the start of the experiment, the vaccine was orally administered on day 0 by feeding the fish with feed containing the vaccine at $4 \%$ body weight twice; at 8 am and $3 \mathrm{pm}$. To ensure that all treated fish received the feed-based vaccine, they were deprived of feed for $24 \mathrm{~h}$ and while feeding, the feed-based vaccine was distributed slowly and evenly in each glass aquaria. For single booster group, vaccination was repeated on day 14, while the double booster group received the feed-based vaccine on days 14 and 42 . The unvaccinated control group was given regular commercial feed without the vaccine. On other days, all fish were fed with normal commercial pellet throughout the 14-week study period.

Serum samples to determine the antibody level were collected from 10 fish of each group at weekly intervals beginning from day 0 until day 98 when the experiment was terminated. The same procedure was replicated and data from both experiments were pooled and analysed.

\section{Challenge trial}

The challenge trial was carried out at week 10 of the experiment. Twenty fish from each of the three groups were transferred into 6 glass aquaria without running water. These 20 selected fish from each group were kept in 2 aquaria at the rate of 10 fish per aquarium as duplicate. A fresh inoculum containing live virulent cells of $S$. agalactiae strain NF958 at a concentration of $1.0 \times 10^{9} \mathrm{CFU} / \mathrm{ml}$ was prepared before $0.5 \mathrm{ml}$ of the inoculum was injected intraperitoneal (i.p.) into each fish. The fish were anaesthetized with Tricaine methanesulfonate (MS-222) prior to the i.p. injection [6]. After challenged, all fish were closely observed at hourly intervals for behavioural and physical changes. Fish that died within the first $6 \mathrm{~h}$ were excluded from the experiment while fish that showed advanced clinical signs of the infection were euthanized. At the end of day 7 post-challenge, all surviving fish were killed by an overdose of MS-222. They were subjected to post-mortem examination before samples of brain, eye 
and kidneys were collected for bacterial isolation. The level of protection or relative percentage survival (RPS) value was then determined [10].

$$
\begin{array}{r}
\text { RPS }=1-(\% \text { immunized group mortality } / \\
\% \text { control group mortality }) \times 100
\end{array}
$$

\section{Bacterial isolation}

Organ samples were streaked onto blood agar and were incubated at $37{ }^{\circ} \mathrm{C}$ for 18 to $24 \mathrm{~h}$. Following incubation dominant colonies were sub-cultured to obtain pure colonies before they were subjected to Gram staining, oxidase and catalase tests. Isolates that were Gram-positive, cocci shaped and catalase negative were subjected to API 20 STREP bacteria identification kit (BioMerieux, France). The Gram-positive cocci but catalase positive were subjected to API STAPH (BioMerieux, France). Similarly, Gram-negative isolates, which were oxidase negative, were subjected to API 20E while those that were oxidase positive were subjected to API 20NE (BioMerieux, France). The API colour codes were referred to the APILAB PLUS program (BioMerieux, France) for species and genus determination of the isolates. Cultures that were identified as $S$. agalactiae by API20 STREP were further confirmed by API 20STREP and BLAST analysis of $16 \mathrm{~S}$ rRNA sequence of PCR product [11].

\section{Enzyme-linked immunosorbent assay}

All serum samples were subjected to indirect ELISA $[12,13]$ that detected the IgM. Coating antigen was prepared by culturing $S$. agalactiae into brain-heart infusion broth and incubated for $24 \mathrm{~h}$ in shaker incubator at $30{ }^{\circ} \mathrm{C}, 150 \mathrm{rpm}$. Bacterial concentration was determined using standard plate count technique before harvested by centrifugation and washed with phosphate buffer saline (PBS). The bacterial pellet was then resuspended in carbonate-bicarbonate buffer ( $\mathrm{pH}$ 9.6) to a final concentration of $2.5 \times 10^{5} \mathrm{CFU} / \mathrm{ml}$. The suspension was boiled in water bath at $97{ }^{\circ} \mathrm{C}$ for $20 \mathrm{~min}$ to kill the bacteria and cooled to room temperature prior to use as coating antigen.

Flat-bottomed microtitre plates were coated with $100 \mu \mathrm{L}$ coating antigen and were left overnight at $4{ }^{\circ} \mathrm{C}$ before washed twice with PBS $+0.05 \%$ Tween 20 (PBST). Then, $200 \mu \mathrm{L}$ of $1 \%$ bovine serum albumin (BSA) was added to block unspecific binding sites and incubated in $37{ }^{\circ} \mathrm{C}$ for $1 \mathrm{~h}$. This was followed by adding $100 \mu \mathrm{L}$ of serum (1:1000) into the reaction and similarly incubated. After that, $100 \mu \mathrm{L}$ of goat anti-tilapia hyperimmune serum, diluted 1:10,000 was added and incubated again. Next, $100 \mu \mathrm{L}$ of conjugated rabbit anti-goat IgMhorseradish peroxidase (Nordic, Netherland) diluted to 1:10,000 was added into the reaction and incubated. After washed for three times with PBST, bound conjugates were detected by adding $100 \mu \mathrm{L}$ of TMB One substrate solution (Promega, USA) before the reaction was stopped with $0.2 \mathrm{~mol} / \mathrm{L}$ sulphuric acid. The absorbance was determined at $450 \mathrm{~nm}$ wavelength (Bio-Rad, USA).

The cut-off value is the highest possible true-positive rate [14] that is used as an indication of protection. It was determined by performing ELISA on 100 serum samples collected from non-immunized tilapia obtained from farms that had no history of streptococcosis infection and did not practice vaccination against the target organism. After subtracting the blank wells, the average OD value was times 2 to get the cut-off value of $0.2 \mathrm{OD}$.

\section{Statistical analysis}

The significance value of the results was calculated by using one way analysis of variance (ANOVA) employed by Tukey HSD in Statistix 9 software (Analytical software, USA). The results were considered as significant at $p<0.05$.

\section{Results}

\section{Serum antibody response}

The serum IgM antibody levels of all groups prior to vaccination showed insignificant $(p>0.05)$ differences. Following vaccination, both vaccinated groups showed significantly $(p<0.05)$ higher IgM levels compared to the control group. Following the first booster dose at week 2 , the increasing pattern continued for both vaccinated groups and reached peak at week 3 . The level, however, started to decrease insignificantly $(p>0.05)$ in the following week but significantly $(p<0.05)$ thereafter to reach the non-protective cut-off value $(p>0.05)$ at weeks 5 and 6 (Fig. 1). In the first 6 weeks postvaccination, both vaccinated groups showed insignificantly $(p>0.05)$ high IgM value. However, following second booster in week 6 , the antibody level significantly $(p<0.05)$ increased again to reach peak at week 8 before declining thereafter until week 12 (Fig. 1). The vaccinated group that received a single booster showed gradual decline in IgM levels to reach the same level $(p>0.05)$ as the cut-off value by week 7 and below the cut-off value thereafter until the end of the experimental period. At time of challenge in week 10, the IgM level of the double booster group was significantly $(p<0.05)$ higher while the single booster and control groups were significantly $(p<0.05)$ lower than the protective cut-off value (Fig. 1).

\section{Challenge trial}

Following intraperitoneal challenge, fish mortality was observed among the control group as early as $24 \mathrm{~h}$ postchallenge. Clinical symptoms were apparent in the control group, which included lethargy, exophthalmia, erratic 


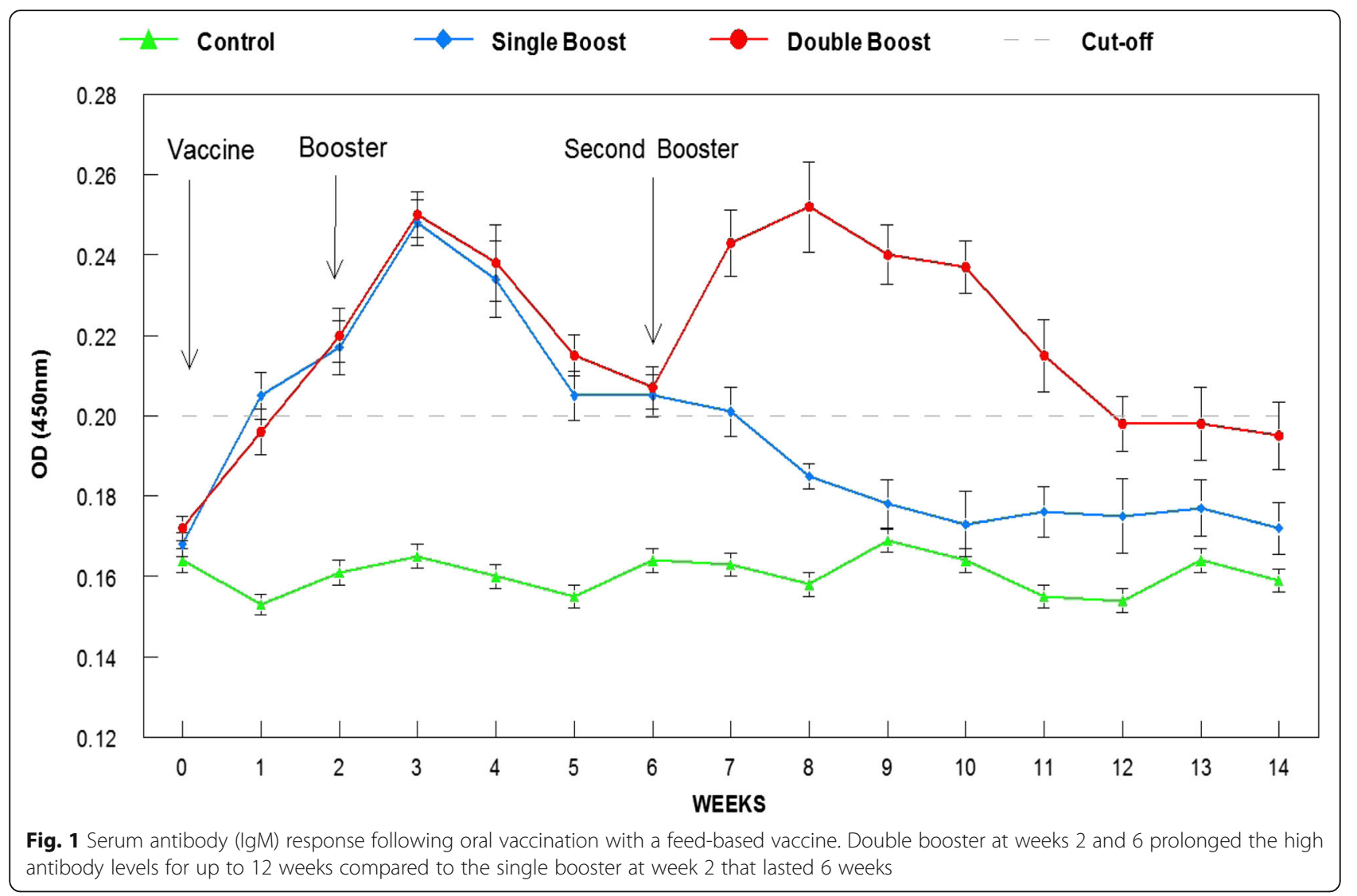

swimming, inflammation at injection area and loss of appetite while few vaccinated fish showed signs of lethargy and loss of appetite. At the end of day 7 post-challenge, none of the unvaccinated control fish had survived compared to $45 \%$ and $70 \%$ survival rates of single and double booster vaccinated fish, respectively (Table 1 ).

Post-mortem examinations revealed congested kidney, enlarged spleen, pale liver and soft, watery brain. Haemorrhages were also registered in various organs including liver, gastrointestinal organs and brain.

\section{Bacterial isolation}

Streptococcus agalactiae was successfully re-isolated from the brain, eye and kidney of all dead fish. The presence of clear zone around cultured colonies was suggestive of $\beta$-haemolytic $S$. agalactiae that was confirmed by BLAST analysis of $16 \mathrm{~S}$ rRNA sequence of PCR product.

\section{Discussion}

As development in aquaculture industry continues to expand, many vaccines against many diseases are made available with the purpose of controlling disease outbreaks. Commercial vaccines for tilapia against streptococcosis are currently available in many countries and are widely used. The most common type of vaccine for streptococcosis is the injectable vaccine, administered via intraperitoneal route as it provides the best protection against streptococcosis. Immersion vaccines such as AQUAVAX $^{\mathrm{ms}}$ and GARVETIL $^{\mathrm{mm}}$ (Intervet Pty. Ltd.) are

Table 1 Comparative fish mortality, survival and relative percentage survival (RPS) between controls unvaccinated fish, fish vaccinated with single booster, and fish vaccinated with double booster regimes followed by intraperitoneal challenge with $0.5 \mathrm{~mL}$ of $1.0 \times 10^{9} \mathrm{CFU} / \mathrm{mL}$ of live Streptococcus agalactiae

\begin{tabular}{|c|c|c|c|c|c|c|c|c|c|c|}
\hline \multirow[t]{2}{*}{ Group } & \multirow[t]{2}{*}{ Number of Fish } & \multicolumn{7}{|c|}{ Mortality (n) Post-challenge } & \multirow{2}{*}{$\begin{array}{l}\text { Survival } \\
\text { Rate (\%) }\end{array}$} & \multirow[t]{2}{*}{ RPS } \\
\hline & & $\mathrm{D} 1$ & D2 & D3 & D4 & D5 & D6 & D7 & & \\
\hline Single Booster & 20 & 6 & 3 & 0 & 1 & 1 & 0 & 0 & 45 & $45^{b}$ \\
\hline Double Booster & 20 & 3 & 2 & 0 & 1 & 0 & 0 & 0 & 70 & $70^{c}$ \\
\hline Control & 20 & 7 & 5 & 3 & 3 & 2 & 0 & 0 & 0 & $0^{\mathrm{a}}$ \\
\hline
\end{tabular}

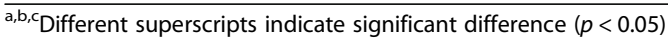


available and are claimed to be more practical for administration but lower in efficacy [5]. The focus of these commercial vaccines, however, was mainly for large farms that can afford high manpower, technicality and facilities for carrying out such vaccinations. Small-scale private farmers in Southeast Asia such as Vietnam, Malaysia, Indonesia and Thailand, however, are unlikely to be able to afford labor-intensive vaccine protocols requiring special equipment. They, therefore, require an easier, cost effective, user friendly and less stressful method of vaccination, which is what oral vaccination can provide [14]. Furthermore, large scale fish producers can also benefit from oral vaccination since an effective, feed-based vaccine could greatly reduce stress in the production fish by avoiding handling during vaccination and lower the cost associated with manpower and equipment.

It is well documented that different routes of vaccination give different intensity of immune response and thus, different vaccine efficacy [13]. Vaccination via intraperitoneal and intramuscular injections triggers a systemic immune response with high antibody levels in a short period of time. This provides longer protection compared to immersion and oral exposure that triggers local mucosal immunity $[15,16]$. Nevertheless, if sufficient amount of antigen is managed to be transported and reach the end gut segment of fish such as carp, both local and systemic immune responses are induced [17]. The second gut segment of fish especially grouper plays an important role in oral vaccination as it participates in the transportation and presentation of antigen from intestinal lumen to intraepithelial macrophages [7]. These macrophages ingest the antigen presented by this route and remigrate from the intestine to lymphoid organs mainly the spleen and kidney before initiating systemic immune response [17]. Similar mechanisms are believed to occur in tilapia.

Our earlier study revealed that feed-based bacterin without adjuvant was able to stimulate IgM response for a brief period of 3 weeks [6]. Addition of incomplete Freund's adjuvant was able to prolong the response to 6 weeks but was not long enough to cover the 3-month critical period. Therefore, in this study, different oral vaccination regimes were tested in trying to maintain immune response and protective efficacy to cover the 3month critical period. Administration of second booster at week 6 resulted in a significant increase in the level of serum IgM for up to week 12, covering the 3-month period required for protection of tilapia during the hot months of April to July. This was further clarified following challenge at week 10 when $45 \%$ and $70 \%$ of the single booster and double booster groups survived, respectively. Therefore, double booster provided longer period of high antibody titre that protected at least $70 \%$ of the fish. This is in agreement with earlier studies that show that a repetition of vaccine dosage or booster dose provides better immune responses and lasting protection $[18,19]$.

A vaccine that provides $70 \%$ protection is considered a good vaccine, but an excellent vaccine provides $>80 \%$ protection [20]. Furthermore, oral vaccination stimulates both mucosal and systemic immune responses, which is an advantage since natural streptococcosis involves entrance of the pathogen through mucosal organs of mouth and skin before entering the blood stream [21]. Naturally, the pathogens initially encounter the mucosal barrier of skin and gut lining before reaching the blood stream. Many studies have highlighted on the presence of some key components of mucosal immunity, particularly the $\operatorname{IgT}$ or IgZ antibody that are associated with mucosal immunity in fish. Furthermore, the role of intestinal $\mathrm{T}$ cells and their functions, particularly in antigen uptake mechanisms at mucosal surfaces has been highlighted, which is important in mucosal vaccination strategies [22]. Similarly, a study in grouper revealed that oral administrations of antigen stimulate the gutassociated lymphoid tissue of the intestine leading to higher level of IgM [7].

\section{Conclusion}

In conclusion, oral vaccination using feed-based vaccine containing formalin-killed bacteria is a viable option in tilapia vaccination against streptococcosis as it can provide systemic immune response against $S$. agalactiae. Administration of second booster dose provides longer period of protection that last for at least 12 weeks at a rate of $70 \%$ protection.

\section{Acknowledgements \\ Technical assistance from Mr. Shahidan, Mr. Fahmi and Mrs Nur Nazifah is gratefully appreciated. \\ Funding \\ The study was partially funded by the AgroBiotechnology Institute, the Ministry of Science, Technology and Innovation Malaysia.}

\section{Availability of data and materials}

The datasets during and/or analysed during the current study are available from the first author on reasonable request.

\section{Authors' contribution}

MSI collected and analysed data, and drafting of manuscript. SZA designed the experiment and revised manuscript. MRMS collected and processes the samples and analysed data. MNAA designed the experiment, analysed data and revised the manuscript. MFN collected and analysed data. MZS designed experiment, analysed data and revised manuscript. All authors read and approved the final manuscript.

\section{Competing interests}

The authors declare that they have no competing interests.

Consent for publication

Not applicable.

Ethics approval and consent to participate

The experiment was approved by the Institutional Animal Care and Use Committee, Universiti Putra Malaysia (IACUC no. R038/2013). 


\section{Author details}

'Department of Veterinary Laboratory Diagnosis, Faculty of Veterinary Medicine, Universiti Putra Malaysia, 43400 Serdang, Malaysia. ${ }^{2}$ National Fish Research and Disease Diagnosis, Fisheries Research Institute, 11960 Batu Maung, Penang, Malaysia. ${ }^{3}$ Department of Biology, Faculty of Science, Universiti Putra Malaysia, 43400 Serdang, Malaysia. ${ }^{4}$ Present address: Institute of Bioscience, Universiti Putra Malaysia, 43400 Serdang, Malaysia.

Received: 22 November 2015 Accepted: 6 September 2016 Published online: 08 September 2016

\section{References}

1. FAO. Cultured aquatic species information programme, Oreochromis niloticus (Linnaeus, 1758). FAO Fisheries and Aquaculture Department; http://www.fao.org/fishery/culturedspecies/Oreochromis_niloticus/en. 2015; Accessed 25 Sept 2015.

2. Zamri-Saad M, Amal MNA, Siti-Zahrah A, Zulkafli AR. Control and prevention of streptococcosis in cultured tilapia in Malaysia: a review. Pertanika J Trop Agric Sci. 2014;37:389-410

3. Amal AMN, Zamri-Saad M. Streptococcosis in tilapia (Oreochromis niloticus): a review. Pertanika J Trop Agric Sci. 2011;34:195-206.

4. Klesius PH, Shoemaker CA, Evans JJ. Efficacy of single and combined Streptococcus iniae vaccine administered by intraperitoneal and intramuscular routes in tilapia (Oreochromis niloticus). Aquaculture. 2000;188:237-46.

5. Silva BC, Martins ML, Jatoba A, Neto CCB, Vieira FN, Pereira GV, Jeronimo GT, Seiffert WQ Mourino JLP. Hematological and immunological responses of Nile tilapia after polyvalent vaccine administration by different routes. Pesq Vet Brasil. 2009;29:874-80.

6. Firdaus-Nawi M, Sabri MY, Hanan Y, Siti-Zahrah A, Zamri-Saad M. Efficacy of feed-based adjuvant vaccine against Streptococcus agalactiae in Oreochromis spp. in Malaysia. Aquacul Res. 2013a;45:87-96.

7. Firdaus-Nawi M, Zamri-Saad M, Nik-Haiha NY, Zuki ABS, Effendy AWM. Histological assessment of intestinal immuno-morphology of tiger grouper juvenile, Epinephelus fuscoguttatus. SpringerPlus. 2013b;2:611-23.

8. Amal MNA, Zamri-Saad M, Siti-Zahrah A, Zulkafli AR. Water quality influences the presence of Streptococcus agalactiae in cage cultured red hybrid tilapia, Oreochromis niloticus x Oreochromis mossambicus. Aquacul Res. 2013:46:313-23.

9. Wohlsen T, Bates J, Vesey G, Robinson WA, Katouli M. Evaluation of the methods for enumerating coliform bacteria from water samples using precise reference standards. Lett Appl Microbil. 2006;42:350-6.

10. Amend DF. Potency testing of fish vaccines. Dev Biol Standard. 1981:49:447-54

11. Abuseliana A, Daud H, Saleha AA, Khairani-Bejo S, Alsaid M. Streptococcus agalactiae the aetiological agent of mass mortality in farmed red tilapia (Oreochromis spp.). J Anim Vet Adv. 2013;9:2640-6.

12. Shelby RA, Shoemaker CA, Evans JJ, Klesius PH. Development of an indirect ELISA to detect humoral responses to Streptococcus iniae infections of Nile tilapia, Oreochromis niloticus. J Appl Aquacul. 2001;11:35-44.

13. Grabowski LD, LaPatra SE, Cain KD. Systemic and mucosal antibody response in tilapia, Oreochromis niloticus (L.) following immunization with Flavobacterium columnare. J Fish Dis. 2004:27:573-81.

14. Holten-Andersen L, Dalsgaard I, Nylen J, Lorenzen N, Buchmann K. Determining Vaccination Frequency in Farmed Rainbow Trout Using Vibrio anguillarum 01 Specific Serum Antibody Measurements. PLoS One. 2012; 7(11):e49672. doi:10.1371/journal.pone.0049672.

15. Rombout JHWM, Kiron V. Mucosal Vaccination of Fish. In: Guddings R, Lillehaug D, Evensen O, editors. Fish Vaccination. Chichester: John Wiley \& Sons, Ltd; 2014. doi:10.1002/9781118806913.ch6.

16. Thune RL, Collins LA, Penta MP. A comparison of immersion, immersion/oral combination and injection methods for the vaccination of channel catfish Ictalurus punctatus against Edwardsiella ictaluri. J World Aquacul Soc. 1997; 28:193-201.

17. Pereira GV, da Silva BC, Vieira FN, Seiffert WQ, Ushizima TT, Mourino JLP, Martins ML. Vaccination strategies with oral booster for surubim hybrid (Pseudoplatystoma corruscans $\times$ P. reticulatum) against haemorrhagic septicaemia. Aquacul Res. 2013:46:1831-41.

18. Rombout JHWM, van den Berg AA. Immunological importance of the second gut segment of carp. I. Uptake and processing of antigens by epithelial cells and macrophages. J Fish Biol. 1989;35:13-22.

19. Chettri JK, Deshmukh S, Holten-Anderssen L, Jaafar RM, Dalsgaard I, Buchman K. Comparative evaluation of administration methods for a vaccine protecting rainbow trout against Yersinia ruckeri 01 biotype 2 infection. Vet Immun Immunopath. 2013;154:42-7.

20. Chettri JK, Jaafar RM, Skov J, Kania PW, Dalsgaard I, Buchman K. Booster immersion vaccination using diluted Yersinia ruckeri bacterin confers protection against ERM in rainbow trout. Aquacult. 2015;440:1-5.

21. Jarp J, Tverdal A. Statistical aspects of fish vaccination trials. Dev Biol Standard. 1997:90:311-20.

22. Iregui CA, Comas J, Vasquez GM, Verjan N. Experimental early pathogenesis of Streptococcus agalactiae infection in red tilapia Oreochromic spp. J Fish Dis. 2016;39:205-15

\section{Submit your next manuscript to BioMed Central and we will help you at every step:}

- We accept pre-submission inquiries

- Our selector tool helps you to find the most relevant journal

- We provide round the clock customer support

- Convenient online submission

- Thorough peer review

- Inclusion in PubMed and all major indexing services

- Maximum visibility for your research

Submit your manuscript at www.biomedcentral.com/submit
Biomed Central 